\title{
Implementasi Algoritma Learning Vector Quantization (LVQ) Pada Prediksi Produksi Tandan Buah Segar Pada Perkebunan Kelapa Sawit
}

\author{
Mawaddah Harahap ${ }^{1}$, Ade Mutia ${ }^{2}$, David Benny Martulus Simatupang ${ }^{3}$, Benyamin Sahputra Gurning ${ }^{4}$ \\ Adinda Utari Putri ${ }^{5}$ \\ 1,2,3,4,5 Program Studi Teknik Informatika, Universitas Prima Indonesia
}

\begin{tabular}{|c|c|}
\hline Article Info & ABSTRAK \\
\hline $\begin{array}{l}\text { Article History: } \\
\text { Received Jun } 12^{\text {th }}, 2021 \\
\text { Revised Aug } 20^{\text {th }}, 2021 \\
\text { Accepted Aug } 31^{\text {th }}, 2021\end{array}$ & $\begin{array}{l}\text { Saat ini, kelapa sawit Indonesia telah berkembang menjadi bagian yang paling } \\
\text { penting di dunia. Dari } 64 \text { juta ton produksi sawit dunia, Indonesia } \\
\text { menyumbang lebih dari setengahnya yaitu } 35 \text { juta ton. Produksi tandan buah } \\
\text { segar (TBS) kelapa sawit memerlukan anggaran biaya dalam masa tanam, } \\
\text { pemanenan, pengangkutan serta pengolahannya. Agar anggaran dapat } \\
\text { disiapkan dengan optimal, maka perusahaan harus dapat mengetahui jumlah }\end{array}$ \\
\hline $\begin{array}{l}\text { Kata Kunci: } \\
\text { Learning Vector Quantization } \\
\text { (LVQ) } \\
\text { Prediksi Produksi Tandan } \\
\text { Perkebunan Kelapa Sawit }\end{array}$ & $\begin{array}{l}\text { rencana yang telah ditargetkan berbeda dengan hasil produksi realisasi. Atas } \\
\text { dasar hal ini, prediksi kelapa sawit sangatlah penting. Hasil penelitian bahwa } \\
\text { algoritma LVQ mampu memprediksi hasil produksi kelapa sawit sehinga } \\
\text { hasil prediksi dapat digunakan untuk menjadi acuan target produksi } \\
\text { perusahaan. Hasil prediksi terbaik diperoleh pada Epoch } 5000 \text { pada tahun } 2015 \\
\text { dan tahun } 2016 \text { dengan hasil } 7 \text { bulan pengujian yang sukses yakni pada bulan } \\
\text { Februari, April, Mei, Juni, Juli, Agustus, September, Oktober, dan November }\end{array}$ \\
\hline
\end{tabular}

Copyright $(2021$ STMIK Triguna Dharma. All rights reserved.

\author{
Corresponding Author: *mawaddah@unprimdn.ac.id \\ Nama : Mawaddah Harahap \\ Program Studi : Teknik Informatika \\ Afiliasi : Universitas Prima Indonesia \\ Email: mawaddah@unprimdn.ac.id
}

\section{PENDAHULUAN}

Saat ini, kelapa sawit Indonesia telah berkembang menjadi bagian yang paling penting di dunia. Dalam hal produksi minyak sawit, Indonesia saat ini menjadi nomor satu dan telah mengalahkan Malaysia. Dari 64 juta ton produksi sawit dunia, Indonesia menyumbang lebih dari setengahnya yaitu 35 juta ton[1]. "Target yang ingin kami capai di 2021 ada beberapa yang sudah masuk ke prioritas nasional ada yang prioritas bidang. Prioritas nasional adalah kelapa sawit, kopi, kakao, tebu, cengkeh, lada dan pala," ujar Direktur Jenderal Perkebunan Kementan Kasdi Subagyono [2]. Untuk meningkatkan produksi tandan buah segar pada perkebunan kelapa sawit perlu dilakukan persiapan dengan baik, salah satu caranya adalah meprediksi hasil produksi. Berdasarkan hasil prediksi yang diperoleh mempengaruhi bagaimana cara dan upaya untuk melakukan perbaikan cara atau peningkatan bila mendapatkan hasil yang tidak sesuai dengan yang diinginkan.

Peramalan dapat dilakukan untuk mengetahui kapan suatu peristiwa akan terjadi sehingga tindakan yang tepat dapat dilakukan [13]. Prediksi yang akurat dapat membantu untuk mendapatkan keuntungan yang besar sebanding dengan resiko besar dan ada kesempatan yang sama dalam kehilangan uang [15]. Beberapa penelitian dalam hal prediksi telah dilakukan oleh beberapa penulis sebelumya untuk mendapatkan cara yang efektif dengan hasil yang akurat dalam bidang Jaringan Saraf Tiruan. Memprediksi produksi minyak kelapa sawit mentah (CPO) dengan algoritma cerdas, Jaringan Saraf Tiruan (JST) yang disebut Backpropagation Neural Network (BPNN) [3]. Metode prediksi times series mimiliki tingkat error data yang rendah dan baik yaitu Neural Network dalam memprediksi hasil produksi ikan tuna menggunakan algoritma Neural Network berbasis forward selection [4]. Algoritma K-Nearest Neigbour dengan model sederhana dapat melakukan prediksi terhadap panen padi [5]. Peramalan produksi merupakan bentuk pembuatan keputusan yang dijadikan sebagai landasan dibanyak industri manufaktur dan industri pelayanan [6]. Pada prediksi jumlah kecelakaan 
sepeda motor dengan algoritme genetika menggunakan optimasi pemodelan regresi linear [7]. Produksi merupakan salah satu hasil yang diharapkan dalam sebuah perkebunan, khususnya perkebunan yang bergerak dalam bidang pengolahan minyak kelapa sawit [8].

Algoritma Jaringan Syaraf Tiruan Backpropagation mampu meprediksi data yang baik terutama data yang berkelanjutan terutama pada waktu tertentu [9]. Dari hasil implementasi pengujian algoritma Backpropagation dan LVQ didapatkan bahwa algoritma backpropagation lebih baik dari learning vector quantization dalam pengenalan pola bangun datar geometri [10]. Learning Vector Quantization (LVQ) merupakan suatu metode pengklasifikan pola yang masing-masing output mewakili kategori atau kelas tertentu [16]. Algoritma LVQ merupakan salah satu algoritma klasifikasi yang mampu mengenali dan meniru input output yang telah ditentukan [14]. Untuk mempercepat proses perhitungan secara efektif dan efisien yaitu menggunakan metode Learning Vector Quantization (LVQ) yang dapat mengklasifikasikan data menjadi 4 kelas berdasarkan parameter masukan [11]. Jaringan Syaraf Tiruan terawasi (supervised) sebagai LVQ (Learning Vector Quantization) adalah suatu metode pengklasifikasian pola setiap unit keluaran yang mewakili suatu kategori atau kelompok tertentu [12].

Dalam penelitian ini, berdasarkan uraian tersebut maka penulis mengajukan Algoritma Learning Vector Quantization (LVQ) untuk memprediksi produksi Tandan Buah Segar pada Perkebunan Kelapa Sawit secara efisien.

\section{METODE PENELITIAN}

Dalam perancangan sistem jaringan syaraf tiruan ini, variabel yang digunakan adalah parameter yang mempengaruhi produksi buah kelapa sawit yang meliputi tahun produksi, tahun tanam, bulan, umur, luas area, jumlah pohon, hari kerja serta pemupukan dansebagai outputnya merupakan prediksi jeniskategori produksi.

Data training yang diambil adalah data parameter produksi kelapa sawit selama lima tahun yaitu tahun 2015 sampai 2020, mulai dari Januari sampai dengan Desember pada kebun kelapa sawit yang ditanam tahun 1999, 2000, 2001 dan 2002. Seluruh data yang terkumpul dibagi dalam dua kelompok besar, yaitu data yang berfungsi sebagai masukan untuk proses training dan pengujian serta data yang berfungsi sebagai keluaran. Data yang tergolong sebagai masukan yaitu 12 data dengan 8 variabel parameter yang dijadikan sebagai matriks P dengan ukuran $12 \times 8$, kemudian ditranspos menjadi matriks berukuran $8 \times 12$ yang dijadikan sebagai input pelatihan.

\section{a. Pendefinisian Input dan Target}

Agar data dapat dikenali oleh jaringan maka data harus direpresentasikan ke dalam bentuk numerik, baik variabel maupun isinya yang merupakan masukan parameter beserta kategori dan keluaran yang merupakan prediksi produksi kelapa sawit. Parameter produksi kelapa sawit diubah ke dalam variabel dalam bentuk numerik, yaitu: Tahun Produksi (A); Tahun Tanam (B); Bulan (C); Umur(D); Luas area (E); Jumlah Pohon (F); Hari kerja panen $(\mathrm{G})$; Pemupukan $(\mathrm{H})$.

Data produksi di-training input vektor sebanyak 12 bulan setiap tahunnya dalam 3 kelas sebagai seperti pada Tabel 1 berikut ini.

Tabel 1. Data Training untuk tahun 2015

\begin{tabular}{|c|c|c|c|c|c|c|c|c|c|c|}
\hline \multirow[b]{2}{*}{ No. } & \multirow[b]{2}{*}{ A } & \multirow[b]{2}{*}{ B } & \multicolumn{4}{|c|}{ Parameter Input } & \multirow[b]{2}{*}{ G } & \multirow[b]{2}{*}{$\mathrm{H}$} & \multirow{2}{*}{$\begin{array}{l}\text { Produksi } \\
\text { (ton) }\end{array}$} & \multirow{2}{*}{$\begin{array}{c}\text { Kalibrasi } \\
\text { target }\end{array}$} \\
\hline & & & $\mathrm{C}$ & $\mathrm{D}$ & $\mathrm{E}$ & $\mathrm{F}$ & & & & \\
\hline 1 & 2015 & 1999 & 1 & 16 & 432 & 30672 & 10 & 61.34 & 441,51 & 1 \\
\hline 2 & 2015 & 1999 & 2 & 16 & 432 & 30672 & 10 & 61.34 & 543,15 & 2 \\
\hline 3 & 2015 & 1999 & 3 & 16 & 432 & 30672 & 10 & 61.34 & 453,14 & 1 \\
\hline$\ldots$ & 2015 & 1999 & 4 & 16 & 432 & 30672 & 10 & 61.34 & 403,71 & 1 \\
\hline 12 & 2015 & 1999 & 12 & 16 & 432 & 30672 & 10 & 61.34 & 476,91 & 1 \\
\hline
\end{tabular}

Sesuai dengan tabel pertumbuhan jumlah produksi, sawit yang telah berumur 11 tahun dapat menghasilkan $14.000 \mathrm{~kg} / \mathrm{ha} / \mathrm{tahun}$. Jika dihitung maka akan terlihat seperti berikut.

Produksi per tahun $=432 \mathrm{ha} \times 14.000 \mathrm{~kg} / \mathrm{ha}=6.048 .000 \mathrm{~kg} / \mathrm{tahun}$

Produksi per bulan $=6.048 .000 / 12=504.000 \mathrm{~kg} / \mathrm{bln}$ 
Hasil yang didapat dari perhitungan, normalnya sawit akan menghasilkan $504.000 \mathrm{~kg}$ tiap bulannya. Jika produksi kelapa sawit kurang dari jumlah $(<504.000 \mathrm{~kg})$ tersebut maka sawit dikategorikan kelas produksi rendah. Sebaliknya jika jumlah produksi sawit lebih $(>504.000 \mathrm{~kg})$ dari jumlah normal maka sawit dikategorikan kelas produksi tinggi dapat dilihat pada tabel 4.2 hasil produksi kelapa sawit menurut kelasnya.

\section{b. Penetapan Target}

Dari data diatas diperoleh duaklas produksi kelapa sawit yang diklasifikasikan sebagai berikut yaitu rendah dan tinggi seperti pada Tabel 2

Tabel 2. Kelas Produksi Kelapa Sawit

\begin{tabular}{|c|c|c|c|}
\hline No & Jumlah Produksi (ton) & $\underline{\text { Kelas }}$ & Numerik Kelas \\
\hline 1 & $0-<504$ & Rendah & 1 \\
\hline 2 & $>504$ & Tinggi & 2 \\
\hline
\end{tabular}

Untuk output bernilai 1 berarti produksi rendah dan bernilai 2 berarti produksi tinggi.

\section{c. Pembentukan Jaringan}

Jaringan yang digunakan untuk memprediksi produksi kelapa sawit adalah jaringan saraf tiruan LVQ. Jaringan ini memiliki dua layer, yaitu layer input dengan 8 neuron yaitu tahun tanam, tahun produksi, bulan, umur pohon, luas area, jumlah pohon, jumlah hari kerja panen serta pemupukan, layeroutputdengan 2 neuron. Pemrosesan yang terjadi pada setiap neuron adalah mencari jarak antara suatu vektor inputan ke bobot yang bersangkutan (w1 dan w2). W1 adalah vektor bobot yang menghubungkan setiap neuron pada lapisan input ke neuron pertama pada lapisan output, sedangkan w2 adalah vektor bobot yang menghubungkan setiap neuron pada lapisan input ke neuron kedua pada lapisan output. Fungsi aktifasi F1 akan memetakan y_In1 ke y1=1 apabila $\|\mathrm{x}-\mathrm{w} 1\|<\|\mathrm{x}-\mathrm{w} 2\|$, dan y1=0 jika sebaliknya. Demikian juga yang terjadi pada fungsi aktifasi F2, akan memetakan y_In2 ke y2=1 apabila $\|\mathrm{x}-\mathrm{w} 2\|<\|\mathrm{x}-\mathrm{w} 1\|$, dan y2=0 jika sebaliknya.

Gambar.1 yang menunjukan jaringan LVQ dengan 8unit (neoron) pada lapisan input, dan 2 unit (neuron) pada lapisan output.

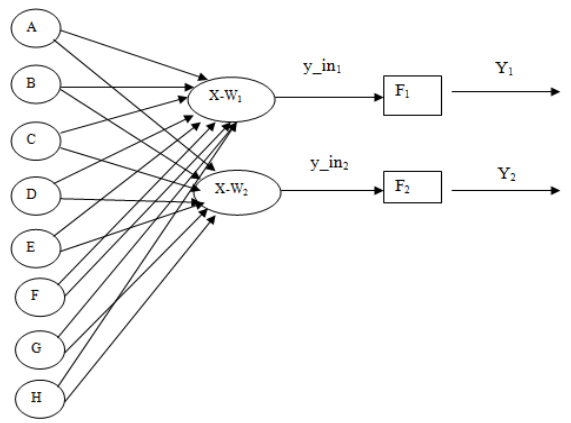

Gambar 1. Arsitektur Jaringan Learning Vector Quantization

\section{d. General Architecture}

Desain Arsitektur adalah perancangan penting yang menggambarkan proses, alur dan interaksi antar komponen dalam suatu sistem. Desain arsitektur dari suatu sistem yang merepresentasikan struktur data komponen pada aplikasi yang diperuntukkan dalam membangun suatu sistem. Perancangan aplikasi ini akan dijabarkan pada arsitektur umum yang terdiri dari General Architecture Training dan Prediksi.

\section{a. General ArchitectureTraining}

General Architecture Training adalah proses-proses yang terjadi dalam pembelajaran jaringan seperti yang dapat dilihat pada Gambar 2 


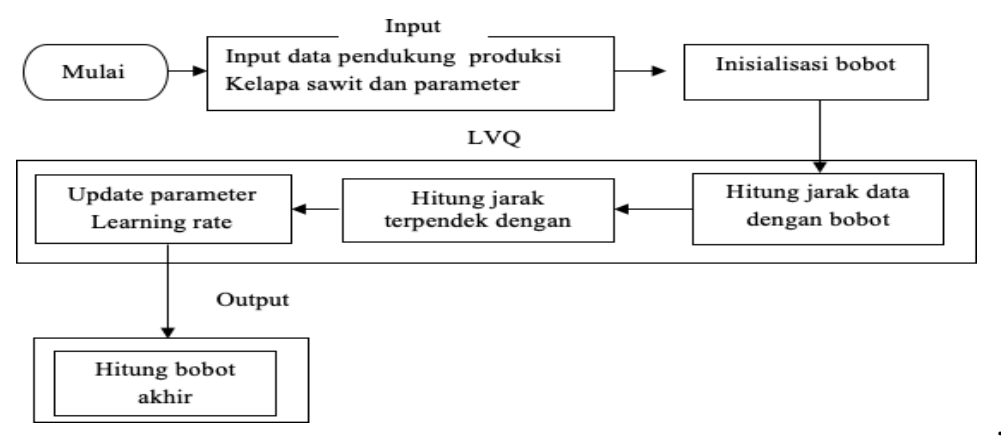

Gambar 2. General ArchitectureTraining

Input jaringan adalah berupa informasi tahun produksi, jumlah pokok, umur, bulan, pupuk, jumlah hari panen dan jumlah produksi. Proses training dengan melakukan perhitungan bobot akhir yang diperlukan pada saat prediksi.

\section{b. General Architecture Prediksi}

General Architecture Prediksi adalah proses-proses yang terjadi dalam penentuan jumlah produksi berdasarkan kelas (rendah atau sedang) seperti yang dapat dilihat pada Gambar 3.

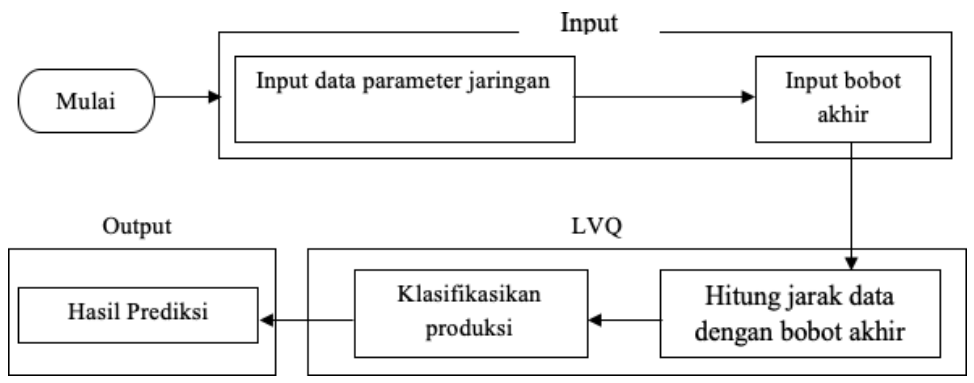

Gambar 3. General Architecture Prediksi

Input data berupa parameter jaringan, parameter produksi tertentu serta bobot akhir yang diperoleh pada saat training. Hasil prediksi berupa klasifikasi produksi rendah atau tinggi.

\section{ANALISA DAN HASIL}

a. Analisa

Produksi tandan buah segar (TBS) kelapa sawit memerlukan anggaran biaya dalam masa tanam, pemanenan, pengangkutan serta pengolahannya. Agar anggaran dapat disiapkan dengan optimal, maka perusahaan harus dapat mengetahui jumlah produksi yang akan dikelola. Produksi TBS sangat dipengaruhi oleh kualitas lahan, iklim antara lain adalah jenis tanah, kedalaman tanah, tinggi tempat, $\mathrm{pH}$ tanah, curah hujan/ tahun, temperatur rata-rata, defisit air ( $\mathrm{mm} /$ tahun), kelembaban udara dan radiasi matahari serta pemupukan.

Produksi tanaman sebagai fungsi dari kualitas lahan dan iklim tersebut dapat diprediksi menggunakan berbagai metode jaringan syaraf tiruan merupakan salah satu metode prediksi yang diakui keunggulannya, terutama untuk prediksi yang melibatkan banyak parameter yang bekerja secara simultan dengan bentuk hubungan fungsional yang tidak linier.

Learning Vector Quantization (LVQ) adalah suatu metode untuk melakukan pembelajaran padalapisan kompetitif yang terawasi (dengan supervisi) dimana jaringan akan secara otomatis belajar untuk mengklasifikasikan vektor-vektor input. Kelas-kelas yang didapatkan sebagai hasil dari lapisan kompetitif ini hanya tergantung pada jarak antara vektor-vektor input. Jika dua vektor input mendekatisama, maka lapisan kompetitif akan meletakkan kedua vektor input tersebut ke dalam kelas yang sama [16].

LVQ merupakan single-layer netpada lapisan masukan yang terkoneksi secara langsung dengan setiap neuron pada lapisan keluaran. Koneksi antar neuron tersebut dihubungkan dengan bobot / weight. Neuronneuron keluaran pada LVQ menyatakan suatu kelas atau kategori tertentu. Kelas-kelas yang didapatkan sebagai hasil dari lapisan kompetitif ini hanya tergantung pada jarak antara vektor-vektor input. Jika 2 vektor input 
mendekati sama, maka lapisan kompetitif akan meletakkan kedua vektor input tersebut ke dalam kelas yang sama [14].

\section{b. Hasil}

Pengujian berfungsi untuk menampilkan informasi hasil pengujian prediksi produksi kelapa sawit. Pada pengujian kali ini, produksi yang akan di prediksi adalah produksi kelapa sawit tahun 2015. Produksi kelapa sawit tahun 2015 telah diketahui. Dapat dilihat pada Tabel 3 hasil produksi kelapa sawit tahun 2015.

Tabel 3. Hasil produksi kelapa sawit tahun 2015

\begin{tabular}{cccc} 
Bulan & $\begin{array}{c}\text { Jumlah Hari } \\
\text { Panen (Hari) }\end{array}$ & $\begin{array}{c}\text { Jumlah } \\
\text { Pupuk(kg) }\end{array}$ & $\begin{array}{c}\text { Jumlah Produksi } \\
\text { Kelapa Sawit }(\mathrm{kg})\end{array}$ \\
\hline Januari & 10 & 61.34 & 441,512 \\
Februari & 10 & 61.34 & 534.155 \\
$\ldots .$. &.. &.. & $\ldots$ \\
Desember & 10 & 61.34 & 476.910 \\
\hline
\end{tabular}

Pada tahun 2015, tanaman sawit berarti telah berumur 11 tahun, karena tahun tanam sawit adalah tahun 1994 dan dengan luas 432 ha. Sesuai dengan tabel pertumbuhan jumlah produksi, sawit yang telah berumur 11 tahun dapat menghasilkan $14.000 \mathrm{~kg} / \mathrm{ha} / \mathrm{tahun}$. Jika dihitung maka akan terlihat seperti berikut.

Produksi per tahun $=432 \mathrm{ha} \times 14.000 \mathrm{~kg} / \mathrm{ha}=6.048 .000 \mathrm{~kg} / \mathrm{tahun}$

Produksi per bulan $=6.048 .000 / 12=504.000 \mathrm{~kg} / \mathrm{bln}$

Hasil yang didapat dari perhitungan, normalnya sawit akan menghasilkan $504.000 \mathrm{~kg}$ tiap bulannya. Jika produksi kelapa sawit kurang dari jumlah $(<504.000 \mathrm{~kg})$ tersebut maka sawit dikategorikan kelas produksi rendah. Sebaliknya jika jumlah produksi sawit lebih $(>504.000 \mathrm{~kg})$ dari jumlah normal maka sawit dikategorikan kelas produksi tinggi. Dapat dilihat pada Tabel 4 hasil produksi kelapa sawit menurut kelasnya.

Tabel 4. Hasil produksi kelapa sawit tahun 2015 menurut kelasnya

\begin{tabular}{ccccc}
\hline Bulan & $\begin{array}{c}\text { Jumlah Hari Panen } \\
\text { (Hari) }\end{array}$ & $\begin{array}{c}\text { Jumlah Pupuk } \\
(\mathrm{kg})\end{array}$ & $\begin{array}{c}\text { Jumlah Produksi } \\
\text { Kelapa Sawit }(\mathrm{kg})\end{array}$ & Kelas \\
\hline Januari & 10 & 61.34 & 441,512 & Rendah \\
Februari & 10 & 61.34 & 534.155 & Tinggi \\
$\ldots$. & $\ldots$ & $\ldots$ & $\ldots$ & $\ldots$ \\
Desember & 10 & 61.34 & 476.910 & Rendah
\end{tabular}

Selanjutkan akan dilakukan pengujian dengan menggunakan aplikasi prediksi produksi kelapa sawit yang telah dirancang. Hasil prediksi produksi kelapa sawit akan dibandingkan dengan hasil produksi kelapa sawit yang sebenarnya. Prediksi akan dilakukan dengan mengubah nilai epoch. Nilai epoch yang akan digunakan 5000 pada tahun 2015, 2016, 2017, 2018, serta 2019. Dapat dilihat Tabel 5 hasil pengujian dengan epoch 5000 pada tahun 2016 dan penurunan alfa tiap epochnya sebesar 0.01 . Jumlah neuron yang digunakan 8 neuron.

Tabel 5. Hasil pengujian Epoch 5000 pada tahun 2016

\begin{tabular}{ccccccc}
\hline \multirow{3}{*}{ Bulan } & $\begin{array}{c}\text { Jumlah } \\
\text { Hari }\end{array}$ & \multicolumn{2}{c}{ Hasil Real } & \multicolumn{2}{c}{ Hasil Prediksi } & \\
\cline { 3 - 5 } & $\begin{array}{c}\text { Panen } \\
\text { (Hari) }\end{array}$ & $\begin{array}{c}\text { Jumlah } \\
\text { produksi } \\
(\mathrm{kg})\end{array}$ & Kelas & $\begin{array}{c}\text { Jumlah } \\
\text { produksi } \\
(\mathrm{kg})\end{array}$ & Kelas & \\
& 10 & 441,512 & Reterangan & \\
\hline Januari & 10 & 534.155 & Tinggi & $>504.000$ & Tinggi & Gagal \\
Februari & 10 & $\ldots$ & $\ldots$ & $\ldots$ & Tinggi & Sukses \\
$\ldots$ & $\ldots$ & & $\ldots$ & $\ldots$ & $\ldots$ \\
Desember & 10 & 476.910 & Rendah & $>504.000$ & Tinggi & Gagal
\end{tabular}

Dari Tabel 5 hasil pengujian epoch 5000 pada tahun 2015 didapatkan 7 bulan dengan hasil pengujian yang sukses. Bulan-bulan yang sukses yakni bulan Februari, Juni, Juli, Agustus, September, Oktober, dan November. Pengertian sukses dalam tabel yaitu hasil prediksi kelapa sawit sama dengan hasil jumlah produksi kelapa sawit yang sebenarnya. Sebaliknya pengertian hasil pengujian yang gagal artinya hasil prediksi kelapa sawit tidak sama dengan hasil produksi kelapa sawit yang sebenarnya. Dan terdapat 5 bulan dengan hasil pengujian yang gagal, yakni pada bulan tersebut adalah bulan Januari, Maret, April, Mei, dan Desember. 
Dari beberapa hasil pengujian yang dilakukan, hasil prediksi produksi terbaik diperoleh pada Epoch 5000 pada tahun 2015 dengan hasil 7 bulan pengujian yang sukses yakni pada bulan Februari, Juni, Juli, Agustus, September, Oktober, dan November dan epoch 5000 pada tahun 2016 dengan hasil 7 bulan pengujian sukses yakni pada bulan April, Mei, Juni, Juli, September, Oktober dan November.

\section{KESIMPULAN}

Setelah merancang dan mengaplikasikan perangkat lunak Algoritma Learning Vector Quantization pada Prediksi Produksi Tandan Buah Segar, maka diperoleh hasil pengujian sebagai berikut:

1. Algoritma Learning Vector Quantization (LVQ) dapat melakukan prediksi produksi kelapa sawit dengan inputan berupa tahun produksi, tahun tanam, bulan, umur pohon, luas area, jumlah pokok, jumlah hari kerja panen serta pemupukan.

2. Hasil prediksi produksi terbaik diperoleh pada Epoch 5000 pada tahun 2010 dan tahun 2011 dengan hasil 7 bulan pengujian yang sukses yakni pada bulan Februari, April, Mei, Juni, Juli, Agustus, September, Oktober, dan November.

\section{REFERENSI}

[1] pse.litbang.pertanian.go.id. (2017). Kelapa Sawit Indonesia Semakin Menjadi Andalan Ekonomi Nasional. Diakses pada 03 Agustus 2021, dari https://pse.litbang.pertanian.go.id/ind/index.php/22-informasi-berita/228-kelapa-sawitindonesia-semakin-menjadi-andalan-ekonomi-nasional

[2] kontan.co.id. (2020). Ini target produksi komoditas perkebunan di 2021. Diakses pada 03 Agustus 2021, dari https://industri.kontan.co.id/news/ini-target-produksi-komoditas-perkebunan-di-2021

[3] Aini, H., Haviluddin, H., Budiman, E., Wati, M., \& Puspitasari, N. (2019). Prediksi Produksi Minyak Kelapa Sawit Menggunakan Metode Backpropagation Neural Network. Sains, Aplikasi, Komputasi dan Teknologi Informasi, 1(1), 24-33.

[4] Suleman, S., \& Pakaya, R. (2018). Prediksi Hasil Produksi Ikan Tuna Menggunakan Algoritma Neural Network Berbasis Forward Selection. Jurnal Technopreneur (JTech), 6(1), 1-10.

[5] Panjaitan, W. T., Utami, E., \& Al Fatta, H. (2018). Prediksi Panen Padi Menggunakan Algoritma k-Nearest Neigbour. SNATIF, 5(1).

[6] Sulistyono, S., \& Sulistiyowati, W. (2018). Peramalan produksi dengan metode regresi linier berganda. PROZIMA (Productivity, Optimization and Manufacturing System Engineering), 1(2), 82-89.

[7] Fraticasari, S. Y. (2017). Optimasi pemodelan regresi linier berganda pada prediksi jumlah kecelakaan sepeda motor dengan algoritme genetika (Doctoral dissertation, Universitas Brawijaya).

[8] Insani, F., \& Harani, I. (2019, November). Peramalan Produksi Tandan Buah Segar (TBS) Kelapa Sawit Dengan Regresi Linear Dan Algoritma Genetika (Studi Kasus: PT. Peputra Masterindo). In Seminar Nasional Teknologi Informasi Komunikasi dan Industri (pp. 262-269).

[9] Saragih, J. R., Hartama, D., \& Wanto, A. (2020). Prediksi Produksi Susu Segar Di Indonesia Menggunakan Algoritma Backpropagation. Jurnal Ilmiah Informatika, 8(01), 58-65.

[10] Hendriyani, Y. (2020). Perbandingan Algoritma Backpropagation Dan Learning Vector Quantization (LVQ) dalam Pengenalan Pola Bangun Ruang Geometri. INVOTEK: Jurnal Inovasi Vokasional dan Teknologi, 20(2), 59-66

[11] Hamidi, R., Furqon, M. T., \& Rahayudi, B. (2017). Implementasi Learning Vector Quantization (LVQ) untuk Klasifikasi Kualitas Air Sungai. Jurnal Pengembangan Teknologi Informasi dan Ilmu Komputer e-ISSN, 2548, $964 X$

[12] Meliawati, R., Soesanto, O., \& Kartini, D. (2016). Penerapan Metode Learning Vector Quantization (LVQ) Pada Prediksi Jurusan Di SMA PGRI 1 Banjarbaru. KLIK-KUMPULAN JURNAL ILMU KOMPUTER, 3(1), 11-20.

[13] Saputra, I., \& Rizki, S. W. Penerapan Metode Learning Vector Quantization Pada Prediksi Intensitas Curah Hujan Di Kota Pontianak. BIMASTER, 8(4).

[14] Harliana, H., \& Kirono, S. (2019). Penerapan Learning Vector Quantization Dalam Memprediksi Jumlah Rumah Tangga Miskin. Jurnal Sains dan Informatika, 5(2), 118-127.

[15] Fitriani, R. R., Ernastuti, E., \& Swedia, E. R. (2019). Algoritma Learning Vector Quantization Dan Fuzzy K-Nn Untuk Prediksi Saham Berdasarkan Pesaing. Jurnal Ilmiah Teknologi dan Rekayasa, 24(1), 1-9.

[16] Usman, W., Damanik, I. S., \& Hardinata, J. T. (2020, September). Jaringan Syaraf Tiruan dengan Metode Learning Vector Quantization (LVQ) dalam Menentukan Klasifikasi Jenis Tilang Berdasarkan Kendaraan. In Prosiding Seminar Nasional Riset Information Science (SENARIS) (Vol. 1, pp. 780-787). 